\title{
The costs of cyberterrorism for the national economy: United States of America vs Egypt
}

\author{
Florentina Stefania NEAGU \\ Bucharest University of Economic Studies, Romania \\ Email: stefanianeagu15@gmail.com
}

PICBE $\mid 983$

\author{
Anca SAVU \\ National Defence University "Carol I", Bucharest, Romania \\ Email: ancasavu91@yahoo.com
}

\begin{abstract}
In recent years cyber terrorism has become increasingly used with the globalization of technology and people's access to high-speed internet. It takes place exclusively in the online environment, the advantage being that it offers an increased level of anonymity to users. Terrorist groups are targeting the misappropriation of social media accounts, focused on Distributed Denial of Service activities, exploiting communications services and banking services for fraudulent misappropriation of financial accounts. Cyberterrorism generates very high costs for the national economy, such as the involvement of specialists for detecting and correcting intrusion, declining productivity and income, costs of information theft, regaining the reputation of an institution or company, the costs relating to the resumption of production and the provision of services, the loss of information concerning intellectual property, financial manipulation using stolen information, the cost of securing computer networks and assuring them in the event of intrusion, costs generated by the time spent on recovering stolen data. In 2018 both the US and Egypt took action on these activities, the US modified its national cyber strategy and Egypt adopted the new law project to combat cybercrime. The main cyber threats they face are: threats of intrusion and sabotage of IT infrastructures, cyberterrorism and cyberwar, threats to digital identity and theft of private data, malware programs. The targets of the attacks were public sector entities, financial organizations, health care organizations, retail and accommodation. The reasons for why hackers attack these organizations are moneyrelated, malware infected by emails, commercial and industrial espionage.
\end{abstract}

Keywords: communication, cyber terrorism, money laundering, underground economy

\section{Introduction}

In order to better understand the costs that cyberterrorism generates in an economy, we must start from the definition of the Federal Bureau of Investigation (FBI) "cyberterrorism is any premeditated, politically motivated attack against information, computer systems, computer programs, and data which results in violence against non-combatant targets by subnational groups or clandestine agents" (Whelan, 2009). In early 1999, cyber terror was not a threat to a state, but 10 years later this threat was recognized by White House Cyber Security Adviser Richard Clarke who called the threat of "infowarfare" instead of cyberterrorism (Brickey, 2012).

Acts of cyberterrorism are made by hackers, state or non-state entities on private computers intentionally acting against the devices, networks and systems of public government and other private networks that benefit from a level of restricted access. The 
type of cyber attack used differs depending on the motivation, affiliation of the attacker to a group, the type of target that is targeted, the technique used, and the time the networks do not work to achieve the desired results.

In the literature, cyberterrorism refers to global terrorist networks that disrupt Internet sites in order to block traffic on them or to access and deactivate military devices, most often hackers attack critical infrastructure systems such as hydropower, central electric or oil refineries. As a result of such attacks, hackers can trigger a real crisis endangering people's safety. In the past, the war was on the ground, but today it has moved into the online environment, thus changing the entire landscape of the war, this war can be worn anywhere in the world, and no big investment or army is required.

\section{Literature review}

Today, computers and computer systems it plays an increasingly important role in developed or developing countries' infrastructures. Confidential information, both public and private, is stored and transmitted through highly sophisticated and interconnected computer networks called the internet. Although the Internet offers a lot of benefits to a number of nations and billions of people, it has become a weapon of today's cyber terrorism. Cybernetic terrorists can attack some major computer networks that may cause essential public services such as water, energy, hospitals, air control, maritime control, etc. (Pitaksantayothin, 2014).

As a result, terrorist attacks of cybernetic nature do not only cause information disasters, but also big economic losses, security problems, all of which are reflected in the welfare of the people. Cyber incidents are caused by: state-affiliated actors perpetrated by outsiders, involved internal actors, featured multiple parties, involved partners. Entities use tactics related to hacking-related breaches leveraged either stolen and/or weak passwords, hacking, over half of breaches included malware, social attacks, errors were causal events in $14 \%$ of breaches an the same proportion involved privilege misuse, physical actions.

The targets of the attacks were public sector entities, financial organizations, health care organizations, retail and accommodation. Motives for attacks were money-related, malware infected by email, commercial and industrial espionage (Verizon Enterprise, 2017).

In order to determine the costs that cyber terrorism generates for US and Egyptian economies, the annual defense budget was analyzed, the Global Cybersecurity Index report assessing the ability of states to implement measures to prevent and counter hostile actions on computer systems.

The Breach Level Index, which is an index calculated annually by Gemalto, a global provider of data and software protection solutions, has been analyzed. The Breach Level Index measures a score according to the five levels of computer intrusion: minimal, moderate, critical, severe, and catastrophic. The index identifies breaches based on country, industry, company, type, source, and date of the incident. As can be seen in Table 1, cyberattacks generate costs for the national economy. 
Table 1. Costs and measures to counter cyber attacks

\begin{tabular}{|c|c|}
\hline General costs for national economy & Measures to counter cyber attacks \\
\hline $\begin{array}{l}\text { Interruption of the supply of electricity and water to } \\
\text { the population. }\end{array}$ & $\begin{array}{l}\text { Configure Intrusion Detection Systems } \\
\text { (IDS) to block malicious domains / IP } \\
\text { addresses. }\end{array}$ \\
\hline $\begin{array}{l}\text { The loss of intellectual property and business } \\
\text { confidential information. }\end{array}$ & $\begin{array}{l}\text { Ensure anti-virus software and definitions } \\
\text { are up to date. }\end{array}$ \\
\hline $\begin{array}{l}\text { Financial manipulation, using stolen sensitive } \\
\text { business information. }\end{array}$ & $\begin{array}{l}\text { Block all unnecessary ports at the Firewall } \\
\text { and Host. }\end{array}$ \\
\hline $\begin{array}{l}\text { Opportunity costs that involve discontinuing } \\
\text { production and services. This interruption is the } \\
\text { result of the ransomware effect, which entails } \\
\text { payments for encrypted data repurchases and } \\
\text { serious disruptions of services and production. }\end{array}$ & $\begin{array}{l}\text { Do not save your passwords or login } \\
\text { credentials in your browser. }\end{array}$ \\
\hline $\begin{array}{l}\text { The cost of securing networks, buying } \\
\text { cyberinsurance, and paying for recovery from } \\
\text { cyberattacks. }\end{array}$ & Irrent with patches \\
\hline $\begin{array}{l}\text { Reputational damage and liability risk for the } \\
\text { hacked company and its brand. }\end{array}$ & $\begin{array}{l}\text { Encrypt in accordance with the data's } \\
\text { classification or sensitivity level. }\end{array}$ \\
\hline $\begin{array}{l}\text { Costs caused by the time that work is being done to } \\
\text { recover stolen data. }\end{array}$ & $\begin{array}{l}\text { Use only removable media approved by } \\
\text { your organization. }\end{array}$ \\
\hline $\begin{array}{l}\text { Costs caused by damage to the devices, it is possible } \\
\text { that a ransomware has been transferred to multiple } \\
\text { devices they need to be replaced. }\end{array}$ & $\begin{array}{l}\text { The need to intensify the enforcement of } \\
\text { national and international law on } \\
\text { cybercrime. }\end{array}$ \\
\hline
\end{tabular}

Source: Authors' own processing, based on McAfee Report and Cybersecurity Awareness

\section{Study case: USA vs Egypt}

At first sight, a cyber attack seems less dangerous than a bomb attack, but such attacks can create unimaginable chaos by destroying the infrastructure and systems that allow society to function. Thus, following cyber-terrorism, the US and other states have adopted legislation to specifically combat cyber terrorism. Under US law, cyber terrorism is treated as an act of terrorism or a particular type of cybercrime.

For example, if we come back 10 years ago, we remember the forced bankruptcy of Lehman Brothers, which triggered the financial crisis of that time. Then the regulators and risk managers, the big bankers around the world focused on supporting banks' ability to withstand financial shocks. But now, as things stand, the crisis may not come from a financial shock, but from a cyber attack that could cause disruption to the capabilities of financial services, especially with regard to payment systems across the board world. Computer criminals and cyber terrorists have always sought ways to infiltrate financial systems. Now, the financial system faces the additional risk of collateral damage, in a wider attack on national critical infrastructure. Such an attack could change confidence in the global financial services system, causing banks, businesses and consumers to be stuck, confused or panicked, which in turn could have a major negative impact on all economic activity.

According to the Harvard Business Review, an attack on a data-processing network or a communications network could cause economic damage of $\$ 50$ billion to $\$ 120$ billion. How could a financial crisis trigger a cyber attack? For example, a so called haterist kid or 
kiddy script, could use a malicious program to launch a cyber attack without taking into account the consequences. Such an attack could have a chain reaction, causing damage beyond the original intent, because magnifying rules and principles are missing from the digital arena.

If a major cyber attack is deliberate or somewhat accidental, the damage can be substantial. Most ATM networks in the US could freeze. Credit cards as well as other payment systems may no longer work, as happened with VISA in the UK. Online banking services could become inaccessible, so without cash, without payments, without reliable information about bank accounts, there could be a widespread but temporary temporary panic.

If we were to look at the attack on September 11, 2001, nicknamed "the new Pearl Harbor," we can say and see that it has destabilized the US economy, while enhancing the world's economic vulnerability. This terrorist attack has more or less influenced all sectors of activity and is also visible in the US national economy. Immediate costs were material damage, human losses, mistrust amongst people in aviation security, which is a drop in airline companies that has repercussions on US national economy. In the short term, New York suffered impressive losses, starting with the reconstruction and rehabilitation of damaged buildings, the cost of which amounted to $\$ 30$ billion. Subsequently, the implications of the US Army have resulted in impressive human spending and losses. As a final calculation, the wars in Afghanistan, Iraq and Pakistan amounted to \$ 4 trillion, which is a huge loss for the US economy (Staneiu, 2017).

But this has also affected neighboring countries around the world, allocating more funds to national security, slightly unstable until the September 11, 2001 event. As a result, the financial resources that could have been used to develop other areas of activity, were directed to security, in order to prevent the spread of terrorism of any kind. The scenery of cyber threats is a huge challenge for security practitioners. The FBI reports that more than 4.000 redundancies occur daily, while other sources of research say that every day 230.000 new malware samples are produced. As a result, global security spending reached its impressive \$ 86.4 billion in 2017, without any downward trend. Gartner had projected $\$ 93$ billion in spending for $\$ 20$ billion in 2018, which is what happened because firewalls and antivirus software prove to be inefficient (Erez, 2018).

From the studies we have done so far, we have seen that national states and other actors engage in cyber attacks to undermine the victim's economy, but such attacks can cause disproportionate economic damage to the size or resources of the attacker. For example, the US has not embraced this terminology and therefore has failed to deliver effective policies (Knake, 2010).

In order to be able to stand before terrorist groups and other actors, the US has to make real investments to increase the security of critical infrastructure, starting with government and military systems, but also with expansion in the private environment. If infrastructure can be turned into a weapon, it should not be connected to the Internet at all, regardless of existing protection measures.

The US must maintain its defense to ensure that any attempt to develop the terrorists is not enough to affect their good work within society. But this involves massive costs. We believe that effective protection against cyber threats, good cooperation between businesses, as well as between the private and the public sectors is needed (The Council of Economic Advisers, 2018). 
Cybernetic connectivity is an important factor in productivity, innovation and growth for the US economy, but it comes at a cost. Companies, individuals, government and other entities are vulnerable to cybernetic activity. Efforts in the public and private sector to combat this dangerous activity could help boost the country's GDP. However, the evolution continues, as well as the magnitude of the cyber threats, all of which suggest that further and continuous efforts are critical, and cooperation between the two public-private sectors is essential.

Egypt faces the same as other states with new types of cyber attacks to disrupt critical services and malware software systems to interrupt or destroy IT infrastructure, energy, nuclear, aviation, health, emergency services and other forms of transport goods and passengers. Infrastructure critical infrastructure systems are vulnerable to complex cyber attacks, even if those systems are not connected to the Internet.

Such cyber attacks take place on several channels, such as e-mail, web sites, social media, but also wired physical systems without Wi-Fi connection.

Types of cyber attacks on Egyptian devices and systems use advanced technologies such as call interception devices, advanced encryption devices, cloud computing, and hacking tools targeting institutional databases or companies.

However, the use of these advanced hacking systems requires an advanced level of knowledge, that is, not every person can make such attacks on systems, you need to have some technical expertise.

At national level, one of the most widespread crimes is identity theft that threatens the security of Internet users and online services. Offenders steal user's personal data, especially those that are available on the Internet, on social prescriptions, various databases, piracy of websites to collect bank account details and unique identification code.

Currently, tools and used for electronic payments can be compromised very easily, which in the long run if countermeasures are not adopted can pose a threat to online payment services. In addition to the influence it can have on companies, it can also affect the data of the institutions, which can lead to the deterioration of reputation and the appreciation of the clients.

In the Cyber Security Strategy 2017-2021, the most affected critical sectors are highlighted: the IT sector including communications satellites, telecommunication networks, Internet service providers; financial services sector including online trading platforms, commercial companies, banks' websites; the energy sector that includes all electricity, oil and natural gas distribution networks. Public service sector that includes government agency websites and national databases. Healthcare and Emergency Services Sector including the national hospital and blood bank network and the transport sector that includes the entire road, rail and maritime transport network (The Egyptian Supreme Cybersecurity Council, 2018).

For the year 2019, the annual budget proposed for cyber security is $\$ 14.9$ billion, rising from $\$ 14.4$ billion in 2018 to $\$ 13.1$ in 2017 (Statista, 2019). While Egypt received a budget of $\$ 2.75$ billion in 2018 for national security, as Egypt stepped up its anti-terrorism efforts (China Global Television Network, 2018).

Starting in 2014, the Global Cybersecurity Index (GCI) is calculated annually to measure the Member States' commitment to national security at national level and to raise awareness among the population. This survey was conducted on a sample of 193 countries, survey questions were divided on the five pillars: legal, technical, organizational and 
cooperation levels. In this ranking, Egypt ranks 14th with a GCI of 0.77 and the United States with a score of 0.91 . The two are in the category of countries that have made all the commitments in terms of computer security.

Cyber space is of particular importance to the Egyptian economy, so this was enshrined in the constitution, Article 31 states that "cyber security is an integral part of the national economic system and security. The state will take the necessary steps to keep it in accordance with the law". The cyber threats faced by Egypt today show that the government needs to act immediately to develop more defensive and offensive capabilities, but it is necessary that all these countermeasures of the cyber war do not restrict citizens' access to information and not to violate their personal life.

The main cyber threats and challenges facing Egypt are: threats of intrusion and sabotage of IT infrastructures, cyberterrorism and cyberwar, threats to digital identity and theft of private data. In order to counteract these threats, the government set out six specific programs in the national security strategy 2017-2021 to ensure citizens' security on the Internet and on electronic networks (Ecofin Agency, 2018).

Globally, we can assess the strength of a country in terms of its cybernetic capability to launch attacks on cyber systems in other countries, the level of dependence on Internet access, and the ability to defend itself against attacks from other countries. United States benefits from strong offensive capabilities while being more vulnerable to cyber attacks compared with North Korea that has a dependency zero in terms of people's access to the Internet, making the country to be considered strong. (Ashour, 2017).

\begin{tabular}{|c|l|}
\hline Incident Type & Ratio of incidents \\
\hline $\begin{array}{c}\text { Web site defacement (Accessing the server that } \\
\text { hosts the site and changing its data) }\end{array}$ & $53.22 \%$ \\
\hline $\begin{array}{c}\text { Mass Defacement(Making defacement in a several } \\
\text { sites which are hosted in the same server }\end{array}$ & $4.81 \%$ \\
\hline $\begin{array}{c}\text { Malware spreading (Downloading malware on victim } \\
\text { machine while browsing an infected site }\end{array}$ & $29.84 \%$ \\
\hline DDOS & $1.3 \%$ \\
\hline Phishing & $4.82 \%$ \\
\hline SQL injection & $0.77 \%$ \\
\hline Spamdexing & $0.6 \%$ \\
\hline Authentication bypass & $0.6 \%$ \\
\hline Others & $4.04 \%$ \\
\hline
\end{tabular}

Table2. Incidents related to incident type in the years 2015-2017 in Egypt

Source: EG-CERT Report

Over the past three years, Egypt has been affected by a series of cyber incidents as seen in Table 2. Egypt has a high internet penetration of 47.4 million users in 2018 and Statista estimates an increase of 50.7 million users in 2019. But most of these users do not benefit from any firewall and malware protection for devices that use them. Egypt imports a lot of devices and software, which makes it have little control over them, some of the government officials use unprotected e-mail and unprotected commercial servers, which makes the country face many threats. 
In 2017, the Egyptian government finalized a draft law on cybercrime and indirect cyberwar. Over the last three years, the government has blocked access to the online Signal encrypted online communications service and Egypt's Al Jazeera post and other sites for their alleged support to terrorist networks. Cyber incidents were $96.8 \%$ resolved, the most affected sectors of the economy were: $35 \%$ the telecoms sector, $32.8 \%$ the government sector, $16.6 \%$ the education sector, $3.7 \%$ the banking and health sectors, $2.8 \%$ the tourism sector (EG-CERT, 2018).

\section{Research and methodology}

In order to determine the link between cyber security costs and the national economy in case of USA, we will use a multiple regression model, this model being used in the macroeconomic analysis to complete the linear regression model (Anghelache et al., 2013).

To highlight the relationship between a dependent (endogenous) variable and two independent (exogenous) variables we will build a multiple regression model in which Gross Domestic Product (GDP) is considered a dependent variable and cyber security spending and number of breaches are variables independent. In order to see what are the parameters of the regression model we will build a series of statistical data based on the information obtained from the Statista database for the period 2010-2018 (Table 3).

The formula of the multiple regression equation is as follows:

$\mathrm{Y}=\mathrm{a}+\mathrm{b}_{1}{ }^{*} \mathrm{X}_{1}+\mathrm{b}_{2} * \mathrm{X}_{2}+\ldots+\mathrm{b}_{\mathrm{p}}{ }^{*} \mathrm{X}_{\mathrm{p}}$

Where:

$\mathrm{Y}=$ represents the estimated value for the dependent variable (GDP)

$a=$ is the point of origin of the line

$\mathrm{X}_{1}=$ Independent Value (Cyber Security Expenditure)

$\mathrm{X}_{2}=$ Independent Value (Number of Breaks)

Table 3. The evolution of GDP, spending on cybersecurity and the number of breaches in USA between 2010-2018

\begin{tabular}{|c|c|c|c|}
\hline Year & $\begin{array}{c}\text { GDP current prices } \\
\text { (billion dollars) } \mathbf{Y}_{\mathbf{x}}\end{array}$ & $\begin{array}{c}\text { Spending on cybersecurity } \\
\text { (billion dollars) } \mathbf{X}_{\mathbf{1}}\end{array}$ & $\begin{array}{c}\text { Number of } \\
\text { breaches } \\
\text { (million) } \mathbf{X}_{\mathbf{2}}\end{array}$ \\
\hline 2010 & 14992.1 & 27.4 & 662.0 \\
\hline 2011 & 15542.6 & 30.5 & 419.0 \\
\hline 2012 & 16197.1 & 34.5 & 447.0 \\
\hline 2013 & 16784.8 & 40.0 & 614.0 \\
\hline 2014 & 17521.8 & 43.5 & 783.0 \\
\hline 2015 & 18219.3 & 49.0 & 781.0 \\
\hline 2016 & 18707.2 & 54.8 & 1093.0 \\
\hline 2017 & 19485.4 & 60.4 & 1579.0 \\
\hline 2018 & 20513.0 & 66.0 & 1244.0 \\
\hline
\end{tabular}

Source: Statista

To identify the typology of the regression function has been made plotting the values of GDP, spending on cyber security and the number of breaches. These three indicators have been selected because the number of breaches determines the annual growth of the cyber 
security budget, and this determines the allocation of a larger share of the Gross Domestic Product to prevent cyber incidents.

Estimation of the regression model was performed using EXCEL-Data Analysis, as can be seen in the table below.

Table 4. Estimating the regression model in EXCEL

\begin{tabular}{|c|c|c|c|c|c|c|c|c|}
\hline \multicolumn{9}{|c|}{ SUMMARY OUTPUT } \\
\hline \multicolumn{9}{|c|}{ Regression Statistics } \\
\hline Multiple R & 0.99849799 & & & & & & & \\
\hline R Square & 0.99699824 & & & & & & & \\
\hline Adjusted R Square & 0.99599766 & & & & & & & \\
\hline Standard Error & 116.870853 & & & & & & & \\
\hline Observations & 9 & & & & & & & \\
\hline \multirow{2}{*}{\multicolumn{9}{|c|}{ ANOVA }} \\
\hline & & & & & & & & \\
\hline & $d f$ & $S S$ & $M S$ & $F$ & Significance $F$ & & & \\
\hline Regression & 2 & 27219656.36 & 13609828.18 & 996.4149 & $2.70474 \mathrm{E}-08$ & & & \\
\hline Residual & 6 & 81952.77824 & 13658.79637 & & & & & \\
\hline \multirow[t]{2}{*}{ Total } & 8 & 27301609.14 & & & & & & \\
\hline & Coefficients & Standard Error & tStat & P-value & Lower 95\% & Upper 95\% & Lower 95.0\% & Upper $95.0 \%$ \\
\hline Intercept & 11219.5283 & 158.9462715 & 70.58692348 & $5.44 \mathrm{E}-10$ & 10830.60079 & 11608.4558 & 10830.60079 & 11608.4558 \\
\hline $\begin{array}{l}\text { Spending on } \\
\text { cybersecurity }\end{array}$ & 149.980144 & 6.524451718 & 22.98739422 & $4.44 \mathrm{E}-07$ & 134.0153855 & 165.944902 & 134.0153855 & 165.944902 \\
\hline $\begin{array}{l}\text { Number of } \\
\text { breaches }\end{array}$ & -0.5142438 & 0.227166609 & -2.263729617 & 0.064218 & -1.07010045 & 0.04161289 & -1.07010045 & 0.04161289 \\
\hline
\end{tabular}

As can be seen in Table 4, there is a direct and very strong link between GDP and cyber security spending and the number of breaches, which is evidenced by the value of Multiple $\mathrm{R}=0.9984$. $\mathrm{R}$ Square represent the determination coefficient that shows the validity of the chosen model to explain the variance of $\mathrm{X}_{1}$ and $\mathrm{X}_{2}$. R Square $=0.9969$ has a value close to 1 , which shows that $\mathrm{X}_{1}$ and $\mathrm{X}_{2}$ explain the variance of $\mathrm{Y}$, in a ratio of $99.69 \%$.

Adjusted R Square is also a determined coefficient of determination with degrees of freedom having the same meaning as $\mathrm{R}$ Square. The number of observations is represented by $n=9$. In order to be able to see which is the correlation between predictors and criterion we will analyze the table ANOVA.

The validity of the regression model is confirmed by the test values, the Fischer Test $(F)=996.4149$ and the very low value of the Significance Test $F=2.70474 \mathrm{E}-08$. Lower 95\% and Upper 95\% represent the lower and upper bounds of the confidence interval for the parameter. We can interpret that the parameters of the regression model are comprised between the following ranges:

$$
\begin{aligned}
& 10830.60079<a<11608.4558 \\
& 134.0153855<b<165.944902 \\
& -1.07010045<c<0.04161289
\end{aligned}
$$

Following the application of the regression model for US case data, the results show that there is a strong link between GDP and cyber security spending, which means that the 
increase in security breaches will increase cyber security spending and implicitly allocating a larger share of GDP for this sector.

Regarding the case of Egypt, protecting critical national infrastructure information, collecting, analyzing and monitoring information on security incidents are managed by Computer Emergency Response Team (CERT-EG) institution subordinated to the National Telecom Regulatory Authority (NTRA). The annual budget allocated for cyber security is not public data The only data that is accessible is the number of cyber incidents as shown in Table 2. The number of incidents increased from 149 in 2011 to 407 in 2017.

\section{Conclusions}

Cyber terrorism generates very high costs for every country, which implied an increase in the annual budget for the prevention and protection of information systems. The analysis of the two US and Egyptian case studies, respectively, shows that cyber-terrorism generates costs for the national economy. Moreover, the results of the regression model show that there is a correlation between the Gross Domestic Product and the cost of cyber security. Intensification of these incidents will determine the states to increase its annual budget to maintain the integrity of the information and servers which store this information.

Cyber terrorism targets government systems, companies and the population, the main purpose of these attacks is to get money from users to return their stolen data. The most affected sectors of the economy were the telecom sector, the government sector, the education sector and the banking sector. Most types of incidents have been related to malware spreading, DDOS, phishing, SQL injection, spamdexing and others.

To prevent cyber-attacks it is necessary to develop cooperation between enterprises and state institutions, it is necessary to improve laws on cyber crime, to develop prevention guides for state and corporate employees, to implement cyber security measures on all devices, and their periodic updating.

\section{References}

Anghelache, C., Pagliacci, M. and Prodan, L. (2013). Model for Macroeconomic- Analyses Based on the Regression Function. Romanian Statistical Review, 1/2013, 5-17.

Ashour, A.S. (2017, June). Egypt's Cyber Dilemma: Technology, Threats and Freedoms. Retrieved from https://egyptianstreets.com/2017/06/04/egypts-cyber-dilemmatechnology-threats-and-freedoms/.

Breach Level Index (2018). Data breach database. A centralized, global database of data breaches with calculations of their severity based on multiple factors. Retrieved from https://breachlevelindex.com/data-breach-database.

China Global Television Network ( 2018, May). Egypt Security: Government urged to increase security budget by $\$ 800 \mathrm{mln}$. Retrieved from https://news.cgtn.com/news/324d444f30454464776c6d636a4e6e62684a4856/sh are_p.html.

Cybersecurity Awareness (no date). Common Cyber Threats: Indicators and Countermeasures. Retrieved from https://securityawareness.usalearning.gov/cybersecurity/data/pdf/Common_Cybe r_Threats_Indicators_and_Countermeasures.pdf. 
Erez, M. (2018, June 22) Cyber attacks are shutting down countries, cities and companies. Here's how to stop them. World Economic Forum, Retrieved from https://www.weforum.org/agenda/2018/06/how-organizations-should-preparefor-cyber-attacks-noam-erez/.

Whelan, R. (2009). A Review of: "Proceedings of the NATO Advanced Research Workshop on Responses to Cyber Terrorism, edited by Centre of Excellence", Terrorism and Political Violence, 21(2), 347-349.

Brickey, J. (2012). Defining Cyberterrorism: Capturing a Broad Range of Activities in Cyberspace, in CTC Sentinel, Combating Terrorism Center at West Point, August, Vol 5, Issue 8, Retrieved from https://ctc.usma.edu/august-2012/.

Constitution of The Arab Republic of Egypt (2014, January 18). Cairo. Retrieved from http://www.sis.gov.eg/Newvr/Dustor-en001.pdf.

Ecofin Agency (2018, December 12). Egypt launches its 2017-2020 national cybersecurity strategy. Retrievedfrom https://www.ecofinagency.com/telecom/1212-39420egypt-launches-its-2017-2020-national-cybersecurity-strategy.

EG-CERT Report (2018). Summary of Incidents in the years 2015, 2016 and 2017. p.2 Retrieved from

http://egcert.eg/wpcontent/uploads/2018/10/SummeryofIncidentsintheyears201 52016and2017.pdf.

Global Cybersecurity Index (2017). International Communication Index. Retrieved from https://www.itu.int/dms_pub/itu-d/opb/str/d-str-gci.01-2017-pdf-e.pdf .

Knake, K.K. (2010, February). Cyberterrorism Hype v. Fact. Council on Foreign Relations, Retrieved from https://www.cfr.org/expert-brief/cyberterrorism-hype-v-fact

McAfee Report (2018, February). Economic Impact of Cybercrime-No Slowing Down. p. 6. Retrieved from https://www.mcafee.com/enterprise/en-us/assets/executivesummaries/es-economic-impact-cybercrime.pdf.

Mee, P., and Schuermann, T., (September 14, 2018 September 14). How a cyber attack could cause the next financial crisis. Harvard Business Review, Retrieved from https://hbr.org/2018/09/how-a-cyber-attack-could-cause-the-next-financial-crisis

Pitaksantayothin, J. (2014). Cyber Terrorism Laws in the United States, the United Kingdom and Thailand : A Comparative Study . Law Journal Faculty of Law Chulalongkorn University, 32 (2),169-185.

The Council of Economic Advisers (2018, February). The Cost of Malicious Cyber Activity to the U.S. Economy. Retrieved from https://www.whitehouse.gov/wpcontent/uploads/2018/03/The-Cost-of-Malicious-Cyber-Activity-to-the-U.S.Economy.pdf.

The Egyptian Supreme Cybersecurity Council, (2018). National Cybersecurity Strategy 2017-2021Arab. http://www.mcit.gov.eg/Publication/Publication Summary/6132

Staneiu, R.M., (2017, May). Impactul 9/11 asupra economiei mondiale. Qvorum Institute, Retrieved from http://qvorum.ro/impactul-911-asupra-economiei-mondiale/.

Statista (2019). Number of internet users in Egypt from 2013 to 2019 (in millions). Retrieved from https://www.statista.com/statistics/462957/internet-users-egypt/

Statista (2019). Proposed budget of the U.S. government for cyber security in FY 2017 to 2019 (in billion U.S. dollars). Retrieved from https://www.statista.com/statistics/675399/us-government-spending-cybersecurity/. 
Verizon Enterprise (2017). Data Breach Investigations Report 10th Edition. Retrieved from https://www.ictsecuritymagazine.com/wp-content/uploads/2017-Data-BreachInvestigations-Report.pdf. 